\title{
LAS MUJERES HUAMANGUINAS EN LA REPRESENTACIÓN DE LOS INTELECTUALES: 1900-1940
}

\author{
Juan GUTIÉRREZ MARTÍNEZ \\ Universidad Nacional San Cristóbal de Huamanga \\ jgutierrez@hotmail.com
}

\section{RESUMEN}

En su primera parte, el trabajo muestra que la vida intelectual huamanguina fue dinámica; más aún los primeros años de estudio ésta actividad se acrecienta y paralelamente se renuevan los temas a tratar. En la segunda parte, se muestran las imágenes y representaciones elaboradas por los intelectuales acerca de las mujeres mestizas huamanguinas. El mensaje de los discursos intelectuales, evidencia un cierto cuestionamiento al "modelo ideal" de mujer "sumisa" y "obediente" al varón; estereotipo que se mantuvo por mucho tiempo en el imaginario de los pobladores de Huamanga como algo "natural", cuyo origen se encuentra en la formación del sistema social patriarcal instituido como resultado de un proceso histórico vinculado con la cultura y las relaciones de poder que predominaron y asignaron a las mujeres espacios físicos y simbólicos.

\section{PALABRAS CLAVE:}

1. Representaciones Intelectuales, 2. Mujer Mestiza, 3. Estigma, 4. Educación.

\section{HUAMANGUIN WOMEN IN THE REPRESENTATION OF THE INTELLECTUALS: 1900-1940.}

\begin{abstract}
In its first part, the work shows that the Huamanguina intellectual life was dynamic; even more the first years of study this activity is increased and in parallel the topics to be treated are renewed. In the second part, the images and representations elaborated by the intellectuals about the mestizas Huamanguinas women are shown. The message of the intellectual discourses, shows a certain questioning to the "ideal model" of a woman "submissive" and "obedient" to the male; stereotype that remained for a long time in the imaginary of the Huamanga settlers as something "natural", whose origin lies in the formation of the patriarchal social system instituted as a result of a historical process linked to the culture and power relations that predominated and assigned women physical and symbolic spaces.
\end{abstract}

\section{KEYWORDS}

1. Intellectual Representations, 2. Mixed Woman, 3. Stigma, 4. Education.

Recibido: $19 / 3 / 2017$

Aprobado: 15/10/2017 


\section{Introducción}

El propósito del presente trabajo de investigación es reconstruir las imágenes y representaciones elaboradas por los intelectuales huamanguinos sobre las mujeres mestizas que fueron descritas y publicadas en los periódicos y revistas de difusión local entre los años de 1900 a 1940.

El mensaje de los discursos de la elite intelectual huamanguina, evidencia un cierto cuestionamiento al "modelo ideal" de mujer "sumisa" y "obediente al varón; estereotipo que se mantuvo por mucho tiempo en la mentalidad de los pobladores de Huamanga como algo "natural" y "universal", cuyo origen se encuentra en la formación del sistema social patriarcal instituido como resultado de un proceso histórico vinculado con la cultura, el conocimiento y las relaciones de poder que predominaron y asignaron a las mujeres espacios físicos y simbólicos que no han sido adoptadas por ellas.

Asimismo, uno de los aspectos que más llama la atención está no sólo en considerar a las mujeres como seres socialmente "inferiores" sino también "frágiles física y moralmente", que significa tener menos capacidad intelectual y la carencia de habilidades para la realización de determinados trabajos. Se atribuye el origen del machismo a la mayor debilidad de las mujeres, su menor contextura física y muscular y por ende, la superioridad física de los varones.

De esta manera, en el imaginario de los intelectuales, la educación se presenta como un elemento imprescindible para lograr avanzar en la eliminación de los problemas tradicionales predominantes de las mujeres y crear una determinada forma de ser, una imagen femenina de la época; corroborando de esta manera a las influencias de las ideologías del nacionalismo pensada desde el Estado como la estrategia más eficaz para lograr la irresuelta tarea de integración nacional de la población y abrir el camino a la prosperidad con justicia y a la vez coadyuvar a la consolidación de la nación peruana. En ese sentido, la mujer educada emergía como la futura propulsora, plena de inspiración dentro del movimiento de la justicia y equidad.

La metodología utilizada se ha basado en la revisión y selección de los periódicos y revistas de circulación local durante la época en estudio que se encuentran en la Biblioteca del Instituto Nacional de Cultura-Ayacucho, y también en el Área de Referencia de la Biblioteca Central de la Universidad Nacional de San Cristóbal de Huamanga.

Hemos estructurado la investigación en dos partes, en la primera parte el presente trabajo muestra que la vida intelectual huamanguina fue dinámica; más aún los primeros años de estudio esta actividad se acrecienta y paralelamente se renuevan los temas a tratar. Es la época en que se divulgan revistas y periódicos de circulación local en los cuales salieron publicadas una variedad de ideas y opiniones sobre la ciudad y su gente. En la segunda parte, se muestran las imágenes y representaciones elaboradas por los intelectuales acerca de las mujeres mestizas huamanguinas, presentadas como las "mestizas cultas" ya que tuvieron acceso a la educación, incluso ellas llegaron a alcanzar carreras y profesiones universitarias. 


\section{Los intelectuales huamanguinos: Realidad y discurso}

En la ciudad de Huamanga la actividad intelectual siempre fue intensa. Más aún a partir de los primeros años del presente siglo esta actividad se acrecienta y a la par se renuevan los temas a investigar. Entre los hechos que conllevaron a la dinamización de la actividad intelectual, tenemos la acelerada modernización-migración, urbanización, irrupción de una generación letrada, entre periodistas, maestros de escuelas, abogados, empezaron a "ampliar el ejercicio de las letras".

El afán por la actividad cultural y académica en la ciudad se explican por la presencia y circulación de un gran número de periódicos y revistas de producción local, donde saldrán publicadas una variedad de ideas y opiniones sobre la ciudad y su gente. Los materiales editados fueron más que impresos de anuncios de bando o pasquín, medios especializados de investigación (Revista Huamanga).

En este período se divulgaron grandes revistas de difusión local como se muestra a continuación: El Granito, Variedades, Fraternidad, y la que más sobresalió fue la Revista Huamanga, etc. Entre los periódicos tenemos: El Siglo, La Época, La Abeja, El Estandarte Católico, La Hormiga, entre otros.

El nuevo tiempo se muestra como una etapa de progreso en la evolución sociocultural del país en el cual la intelectualidad provinciana asumió una activa representación en la elaboración de discursos y en la conducción de influencias en las decisiones, sobre todo por su fácil acceso a los cargos públicos y de poder durante la época en estudio.

"... Desde que el Centro no cuenta con medios para ejecutar obras de progreso material, ha tomado a su cargo la misión elevada y trascendental, de estimular la consagración de nuestros intelectuales y amantes al estudio, de investigar y señalar los factores que debemos poner en juego para satisfacer ese común anhelo de forjar el resurgimiento integral de nuestro querido terruño, respetando al mismo tiempo nuestras tradiciones e historia autóctona..." 1

De esta manera, los espacios públicos como las plazas, las celebraciones colectivas, las ceremonias, fueron dotados de nuevos contenidos. Para que ello suceda, hubo un vehículo generador y dinámico por excelencia: la comunicación colectiva. Esa comunicación se concretó y materializó en la prensa escrita.

Entre los intelectuales más destacados de la época por sus ideales y su inquietud por la comprensión e investigación de la problemática local se indica a continuación:

Manuel Antonio Hierro Pozo, realizó sus estudios superiores en la "Escuela Normal de Varones de Lima" entre los años de 1907. Pensador de tendencia liberal -preocupado por el conocimiento de la situación de retraso económico y social que vivía la ciudad y su gente; buscó plantear propuestas de cambio y desarrollo a través de sus investigaciones. Entre sus obras más importantes figuran: "La Decadencia de Huamanga y su Resurgimiento, "La Escuela Rural Andina", entre otros.

Manuel E. Bustamante, en 1907 volvió con el título de normalista de segundo grado. Ocupó cargos importantes como director de colegios y el Instituto de Preceptores, fue

1 Revista Huamanga, Núm. 17. Ayacucho, 1939. Redacción Luis Milón Bendezú. 
teniente alcalde, director de "La Revista Huamanga", entre sus obras más importantes destacan: "Apuntes para el folklore peruano", "La mendicidad en Ayacucho", "Las mujeres preceptoras", "Los indios y la instrucción pública”, etc.

Lucio Alvizuri Bendezú, realizó sus estudios superiores en la "Escuela Normal de Varones de Lima", fue pintor y escritor de talla, sus dibujos aparecen en las portadas de la Revista Huamanga.

Como se observa las publicaciones se caracterizaron por un extraordinario nivel de independencia, libertad que se expresaban no sólo en las opiniones políticas relacionados con el partido de gobierno sino también en aspectos de ataques personales.

Los periódicos no eran instrumentos de debates ideológicos sino de artículos de naturaleza cuasi científica que describían acontecimientos de trascendencia regional e incluso de análisis de opiniones y corrientes intelectuales europeas. Las discusiones sobre el estado y la sociedad tomaron en cuenta a las mujeres como ciudadanas potenciales.

De este modo un apasionado y esforzado espacio encontró pretexto en las páginas de los periódicos y revistas impresos que no se cansaban de salir a la "luz pública".

La inquietud primordial de los intelectuales huamanguinos durante el período estudiado fue abordar los problemas más urgentes que agobiaban a la región, ésta se evidencia en sus discursos y representaciones divulgadas en los periódicos y revistas de publicación local, entre los cuales se indican: temas relacionados a la construcción de una identidad regional (Pokras), estudios sociales, históricos, estudios relacionados a propuestas de desarrollo, folklore, pobreza, entre otros.

"...Hasta ahora "Huamanga" ha sido honrada con la colaboración de contados elementos, pero esto no basta para la finalidad que persigue, cual es de ser tribuna de quienes dedican sus desvelos, esfuerzos al estudio de nuestros problemas locales; seguramente hay muchos que escrutan el porvenir, investigan calladamente diversos tópicos que se refieren al futuro de nuestro pueblo, pero que sienten recelo de dar a la publicidad para evitarse criticas egoístas de muchos que nada hacen ni quieren dejar hacer..."

La visión era que la modernización, los circuitos ideológicos del nacionalismo y la ciudad letrada se extendieran al campo para configurar y describir paisajes sociales y costumbres del interior. Esto como parte de un proceso de masificación de las letras, donde las ciudades pierden el privilegio y los monopolios educativos; influenciando enormemente en los intelectuales huamanguinos de la época; entonces, la educación aparece como opción y alternativa, "como la panacea" para afrontar diferentes problemas regionales.

Fue un período intenso en la producción de ideas, los intelectuales exploraron y crearon mapas mentales de la región, clasificando en ellos a las personas y los sectores sociales que componen la región. Como resultado, diversos procesos de "imaginación de nación" dieron lugar a una gran variedad de tratados de geografía, publicaciones de diverso orden, llenos de ilustraciones que circularon consolidando así imágenes de nación racialmente diversos, con grupos étnicos diferentes y discretos, habitando cada zona de las

2 Revista Huamanga, Núm. 17. Ayacucho, 1939. 
regiones, cada una con sus particularidades. Rosa Escarcena, hace una clasificación social de la región de Ayacucho en los siguientes términos:

"El indio ayacuchano: indio rustico/india rustica- (Purun Runa o salcca - runa). Indio/ india semicivilizado - campesino (chacra runa). Indio/india civilizado (llacta runa). Indio/ india mestiza - plebeyo ( macctas o cholos). Indio/india mestizo plebeyo. Indio/india mestizo culto".

En efecto, el tono de muchos escritos contenidos en revistas y periódicos de difusión local elaborado por los ayacuchanos de entonces expresa, entre otras cosas, la necesidad de definir y determinar las características de sus habitantes, ya que el contexto era apropiado por la cercanía de la celebración de varios hechos de trascendencia regional; es decir, los discursos están marcados por los efectos de la coyuntura.

En consecuencia, las ideas y proyectos que se habían difundido con tanta fuerza desde el Estado estaban sujetas a las ideas de modernización y la ideología del nacionalismo, lo cual obligaba, no solamente en enseñar a leer, escribir y difundir la aritmética, sino ante todo en transmitir el "idioma nacional", que era el castellano, masificar un discurso de historia y geografía nacional, inculcar los hábitos alimenticios que mejorasen las condiciones físicas de la raza indígena, así como nociones de higiene y "urbanidad".

"Los elevados fines que persigue nuestra educación e instrucción concordante con la aspiración nacional hace que nuevamente fluya de nuestra mente, lo que ya es dogma y axioma de que nuestra enseñanza en su forma y en sus fines, tiendan a la disminución del analfabetismo, como premisa para la forjacion de la nueva masa ciudadana, consciente de su rol social y del más puro patriotismo y que con el pensamiento de analizary profundizar nuestra observación, no abrigamos otra mente, que mostrar su estado actual, para que bien meditada y mejor encaminada llene principios, medias y fines, tal como espera el anhelo nacional". (Lucio Alvizuri).

Estas demandas se cristalizaron en plataformas de reivindicación intelectual huamanguina, cuyas referencias se encuentran en la constitución del Comité Pro Centenario de la Batalla de Ayacucho en 1918.

Las décadas de 1920 a 1940, se muestran como una coyuntura particular para la población ayacuchana por la proximidad de las conmemoraciones de un conjunto de gestas históricas trascendentales que le consintieron hacer cambios favorablemente al interior de la ciudad, entre ellos tenemos: primero, en su arquitectura urbana y la segunda, se emprenden estudios rigurosos sobre la región. Para de esa manera tener un mejor conocimiento de la ciudad, favoreciendo la útil modernización urbana (Caro: 2000).

Entre los acontecimientos de trascendencia histórica que llamaron la atención de los medios intelectuales y políticos del país y por ende de la región, se mencionan: la conmemoración del Centenario de la Independencia Nacional, el Centenario de la Batalla de Ayacucho, los Centenarios de la Fundación Española de varias ciudades, entre las que se encontraba Ayacucho, entre otros, propiciaron la organización de celebraciones, en algunos casos fastuosos y la exaltación nacionalista y los sentimientos regionalistas. También el ambiente generado permitió la reflexión sobre estos hechos y sobre su influencia en los procesos históricos regionales y su situación actual. 
Acontecimientos representativos que le permitieron ejecutar cambios importantes en la imagen de la ciudad, pensando en la buena acogida que se debía hacer a las delegaciones nacionales e internacionales; entre los cambios a ejecutarse se mencionan; primero, remozar la infraestructura urbana; $y$ la segunda, obtener un mejor conocimiento de la región; es decir, investigar sobre su historia y su geografía. En gran medida estos acontecimientos posibilitaron una modernización urbana de la ciudad de Ayacucho.

En este contexto Huamanga se caracterizaba por ser una sociedad rural, con fuertes rasgos coloniales -calles muy estrechas y una arquitectura urbanística predominantemente colonial- cuya distribución urbanística expresaba a la organización social de la época. Este patrón colonial sufre trastoques a partir de las primeras décadas del siglo, debido a la mayor presencia de gente procedente de diversas partes por la construcción de vías de comunicación.

Del mismo modo, la proximidad de las festividades en conmemoración de los eventos señalados, hacen que los vecinos notables (autoridades representativas de la localidad) y los miembros de la elite intelectual local decidieran organizarse en una institución "cultural" con propósitos concretos de dar a conocer los problemas más urgentes de la región y sus propuestas de desarrollo. Entre ellos, tenemos: gestionar la ejecución de las obras más importantes de saneamiento y ornato de la ciudad de Ayacucho.

Con estas referencias era de esperarse la emergencia y constitución de un grupo cultural regional sólido, más aún en un momento en que los discursos regionales se mostraban vigorosos. De esta manera, el "Centro Cultural Ayacucho", fue creado para encubar (sic) grandes ideales de progreso y prosperidad, ya que el contexto representó un momento de desarrollo en la evolución sociocultural del país, donde la intelectualidad provinciana tuvo una activa representación en la construcción de discursos y el manejo de influencias en las decisiones políticas, sobre todo, por su fácil acceso a los cargos públicos y de poder durante este contexto.

"...Con el significativo título de "Huamanga, saca a luz su órgano de publicación bimestral el "Centro Cultural Ayacucho". Colabora en sus páginas un prestigioso núcleo de intelectuales humanguinos aportando sus valiosos conocimientos científicos, literarios y artísticos. La obra en que está empeñado ese grupo de espíritus luchadores constituyen un afán de renovación, pues tienen la intención de que Huamanga está en el momento de su confrontación, para recuperar su primer puesto..."13

Como señala Urrutia, la construcción de "una entidad" de país en el siglo XIX estuvo asociada a la idea y la construcción del Estado nación, para lo cual el requisito indispensable era la existencia de élites "inventoras" que construyan "la identidad nacional". Esta construcción de identidad, además de "rehacer" la hostia, necesitó inventarse sus propias tradiciones, sus mitos y ritos colectivos, en suma su propio imaginario que, desde el control del estado, buscó expandir los referentes ideológicos "nacionales" que fueron luego transmitidos culturalmente.

3 Revista Huamanga, Núm. 15. Año IV. Ayacucho, 1932. 


\section{Mestiza huamanguina en la representación de los intelectuales}

Sería imposible concebir la historia de las mujeres sin una historia de las representaciones, percepciones, decodificación de las imágenes y discursos que expresan la evolución del imaginario masculino y del entorno social que los limita al espacio doméstico.

Desde esta perspectiva, si pretendemos estudiar la imagen de las mujeres huamanguinas es imprescindible analizar las representaciones que las envuelven. Intelectuales, educadores y directores espirituales, señalaron que era lo propio de su mundo, creándoles un modelo de conducta y personalidad donde pureza, honor, sumisión y obediencia al hombre las apoyaba y redimía. De esta manera, durante mucho tiempo, la historia fue de los hombres, a quienes se los concebía como únicos representantes de la humanidad.

El mensaje de los discursos de la élite intelectual huamanguina, evidencia un cierto cuestionamiento al "modelo ideal" de mujer "sumisa" y "obediente" al varón; estereotipo que se mantuvo por mucho tiempo en la mentalidad de los pobladores de Huamanga como algo "natural" y "universal", cuyo origen se encuentra en la formación del sistema social patriarcal instituido como resultado de un proceso histórico vinculado con la cultura, el conocimiento y las relaciones de poder que predominaron y asignaron a las mujeres espacios físicos y simbólicos que no han sido adoptados por las mujeres.

Estas representaciones presentadas y descritas en los periódicos correspondieron al engranaje de los sistemas sociales que concibieron a las mujeres como "seres inferiores" y "marginadas", donde las funciones sociales, tales como las domésticas y ciertas conductas, como la dulzura y la paciencia eran establecidas e imaginadas y a la vez eran muy idóneas para desempeñar las labores que les fueron asignadas a ellas con anterioridad.

En consecuencia, fueron las sociedades patriarcales que han instituido el orden jerarquizado de las relaciones sociales basadas en una ideología que la sustente, dándole apariencia científica que justifique y perpetúe las desigualdades sociales entre los varones y las mujeres. No obstante, estas imágenes femeninas correspondieron a categorías de clasificación y jerarquización que operaron como elementos estructurantes de las relaciones sociales imperantes, influyendo tanto en los procesos identitarios como en los mecanismos de discriminación. Es decir, el orden social funciona como una inmensa máquina simbólica que tiende a ratificar la dominación masculina en la que se apoya: la división sexual del trabajo; la estructura del espacio, oposición entre el lugar de reunión o el mercado, entre otros (Bourdieu 2006: 22).

Para los intelectuales huamanguinos, los estereotipos femeninos elaborados en base a las creencias y fantasías masculinas, está atravesando por procesos de cambios y transformaciones en el período que nos ocupa y forma parte de una nueva propuesta, cuya realización otorgaba a las mujeres un rol crucial acorde a las demandas de la nueva realidad; ya que ellas se encuentran en vías de elevar y transformar sus potencialidades personales e intelectuales al siguiente estado de poder considerarse más capaces e independientes para sí mismas. 
De esta manera, la idea estigmatizada sobre la mujer huamanguina, socialmente relegada a espacios y lugares inferiores al de los varones; $y$, también las reglas que circunscribían a las imaginadas por las leyes, la iglesia, la sociedad a las que debían asemejarse las mujeres de toda condición; están siendo superadas por las educadas; dado que la enseñanza reviste una importancia capital para definir el lugar que la mujer ocupe en la sociedad.

Sin embargo, en sus inicios había ciertos factores que restringían el desarrollo de la educación integral de las mujeres, imposibilitando que pudieran alcanzar una educación superior que contemplara el desarrollo de las áreas del conocimiento científico y profesional. Estas consideraciones hacían alusión a la incapacidad intelectual y de carácter de las mujeres para el conocimiento académico y la incompatibilidad del rol natural de las mujeres con su profesionalización. Si bien se consideraba que las mujeres debían ser instruidas, ésta instrucción sólo debía concebirse al ámbito doméstico más no profesional. Se consideraba que había una incompatibilidad entre los roles naturales" y las aspiraciones académicas, pues se consideraba que la misión natural de las mujeres era incompatible con el ejercicio de profesiones especialmente liberales (Valladares 2012).

Sergio Quijada, por ejemplo, propone en estos términos lo que para él garantizaba el cambio de la situación social de la mujer.

"...La mujer en todos los tiempos ha sido objeto de amenazas, censuras por aquellos que han mirado con el mayor desprecio y olvidado su importancia. Viejos perjuicios relegaron a la mujer a lugares inferiores a los del hombre. Pero, la mujer, la verdadera mujer comprensiva a sabido darse cuenta de lo mucho que puede hacer dentro del movimiento de la justicia y equidad; y es que esa mujer educada dentro de la escuela de la nobleza, y de la virtud será la eterna propulsora de la inspiración, del orden, de la ética, de la política y de toda esa gama abstractiva de valores que como una luz semivelada guía los pasos de la humanidad, objetivados en la cultura. De aquí el deber de la madre de guiar los pasos a los hijos de sus entrañas dándoles ejemplos de nobleza, bondad y ternura puesto que la ruina de los niños y la desgracia en esta vida dependen en gran parte de la mujer..."4

La discusión sobre la educación de la mujer se centró en el tipo de estudio que debían seguir de acuerdo a su naturaleza femenina. El condicionamiento para el desarrollo académico de las mujeres se extendió posiblemente desde los estudios primarios pasando por el superior; siendo confirmadas que escogieran las carreras afines con su "naturaleza". Considerando que las mujeres asumieran la misión de hacerse cargo del hogar; por lo que fueron bien vistos que contaran con el conocimiento necesario.

Pero también, según los intelectuales la discriminación de las mujeres se manifestó en la vigencia de un conjunto de estereotipos y prácticas que desvalorizaron a las mujeres, dicha degradación está profundamente arraigada en la creencia sobre el cuerpo y la sexualidad de las mujeres que se traducen en deberes que deben cumplir por "naturaleza" en la familia y en la sociedad.

Asimismo, uno de los aspectos que más llama la atención no sólo está en considerar a las mujeres como seres socialmente inferiores sino también "frágiles física y moralmente",

4 Revista Huamanga, Ayacucho, 1943. Núm. 52 y 53. 
que significa tener menos capacidad intelectual y la carencia de habilidades para la realización de determinados trabajos. Se atribuye el origen del machismo a la mayor debilidad de las mujeres, su menor contextura física y muscular y por ende, la superioridad física de los varones.

La debilidad física o mental en relación con el varón es el rasgo por el que las mujeres son y fueron señaladas como inferiores históricamente en la mayoría de nuestros pueblos. A pesar de haber sido entendido siempre como natural, este rasgo es, como las otras características del cuerpo y de la personalidad humana, construida, fomentada social y culturalmente. Como señala Duby (1992:20), la relación entre los sexos no es un hecho natural, sino una interacción social construida e incesantemente remodelada, consecuencia y al mismo tiempo motor de la dinámica social.

Esta diferencia que refleja la separación social de ambos sexos, se traduce en forma de una división en la que aparece continuamente el papel masculino dominante bajo la forma, no solo de posiciones sociales y políticos objetivos de poder, sino que también, esta diferencia reaparece en situaciones simbólicas que incluyen actitudes, sentimientos y valor; cada uno de los cuales nos revela que determinado grupo sexual constituye en su comportamiento una forma de conciencia de grupo social específico.

De esta manera, en los ideales de los intelectuales huamanguinos la educación pública podía otorgar el antídoto para la "naturaleza" (raza), podía moldear y corregir las desigualdades y los estereotipos negativos, la cual es cruel con las razas incivilizadas; es decir corregir los males con que la historia forjó nuestro devenir. Para la élite intelectual huamanguina, como señala Emma Mannarelli (1989) la escuela es pensada como el lugar privilegiado para cambiar los hábitos y costumbres. Es en la escuela donde el futuro ciudadano y la futura madre de familia deben adquirir las nociones y las buenas modales, sin las cuales más tarde no podrá ser la mujer sana que dé hijos útiles a la patria.

Por otra parte, si bien se reconocía que las mujeres tenían algunas capacidades intelectuales por lo general se ponía en tela de juicio su capacidad académica. Se consideraba que para actuar en la esfera pública eran necesarios ciertos elementos como firmeza de carácter, discernimiento superior y convicción de principios, que por lo general se pensaba que eran escasos en las mujeres.

"...La mujer, considerada como ser, débil física y moralmente, para la lucha por la conservación humana; por su constitución anatómica, se halla en vías de elevar sus aptitudes al estado de poder considerarse más capaz para sí misma y para las que de ella dependen. Tanto las artes como las letras, profesiones e industrias son alcanzadas día a día por un número creciente de individuos de su sexo, llegando a ocupar puestos y adquirir títulos que no hace mucho, se consideraban fuera del radio de su esfera de acción y que hoy mismo encuentran resistencia en los espíritus contrarios a la evolución que esta va sufriendo ante el medio creado por el adelanto humano..."

Como se observa en el fragmento, las mujeres están en proceso de conquista de importantes espacios, en la política, en la ciencia, en las artes por mencionar algunas áreas; gracias a la educación van transgrediendo profundamente las normas sociales

5 Periódico de publicación local “La Patria”, Núm. 2. Año, 1, Ayacucho, 1922. 
tradicionales. Provocando de esta manera en esta coyuntura el nacimiento de un discurso secular, promovido por un grupo vanguardista de intelectuales conformado por educadores y abogados, quienes reflexionaron acerca del ejercicio de la sexualidad y de la organización de la sociedad en general.

De esta manera, en el imaginario de los intelectuales, la educación se presenta como un elemento imprescindible para poder avanzar en la eliminación de los problemas tradicionales predominantes de las mujeres y crear una determinada forma de ser, una imagen femenina de la época; corroborando de esta manera a las influencias de las ideologías del nacionalismo pensada desde el Estado como la estrategia más eficaz para lograr la irresuelta tarea de integración nacional de la población y abrir el camino a la prosperidad con justicia y a la vez coadyuvar a la consolidación de la nación peruana. En ese sentido, la mujer educada emergía como la futura propulsora, plena de inspiración dentro del movimiento de la justicia y equidad.

Asimismo, la educación les permitió a las mujeres una activa y definitiva incorporación a la sociedad que fue fundamental en la construcción de un nuevo orden protagonizado por las mujeres como sujetos sociales. Ideales que reflejaron un amplio cuestionamiento de ciertos sectores sociales tradicionales al poner en tela de juicio los supuestos que naturalizaban y legitimaban la inferioridad de las mujeres con relación a los varones.

En consecuencia, el predominio de los discursos con mensajes preceptivos sobre la vida cotidiana de las mujeres que demandaban ser guardianas del hogar, madre y esposa, acaba siendo desterrada por las mujeres educadas; para ellas la educación se presentaba como un mecanismo más eficaz de "emancipación" que les permitió liberase de los tabúes impuestos por las sociedades tradicionales.

Finalmente, los efectos de las reformas hicieron posible el surgimiento de un nuevo ideal de la mujer huamanguina. El nuevo patrón hizo alusión a la capacidad intelectual de la mujer y su papel social en el progreso de la región y la consolidación de la nación. Bajo este nuevo paradigma, además se promovieron nuevas miradas acerca de la maternidad, el cuidado de los hijos y la constitución del hogar.

De esta manera, en el nuevo contexto histórico, los intelectuales huamanguinos terminan elogiando a la emergencia del nuevo sujeto social, la mujer educada, ya que el proyecto de la elite era alcanzar una nación moderna, compuesta por ciudadanos portadores de derechos de libertad, igualdad y justicia que dieran forma a los derechos universales de los habitantes peruanos; el estado - nación, soberano y homogéneo era la forma específica donde se esperaba la realización del ideal moderno de ciudadanía universal -extendida a todos los ciudadanos (Chatterjee 2007: 177).

Sin duda alguna, la mujer huamanguina ha logrado alcanzar un rol protagónico como ciudadana y como agente de cambio en Huamanga. El siglo XX también es el siglo en el cual las mujeres, cada vez más mujeres, toman la palabra y el control de sus identidades visuales; subrayan las implicaciones políticas de las representaciones, intenta romper los estereotipos y proponen múltiples vías de realización personal (Duby 1992: 20). La capacidad de la mujer para trascender las propias fronteras, para evitar encerrarse en sí misma. 
A este grupo de mujeres podríamos denominar "vanguardistas", pues constituyeron un movimiento intelectual de avanzada para la época. Lo que resulta más significativo, sin embargo, es que las vanguardistas además del nivel de participación que lograron contribuyeron a la creación y ampliación de los espacios públicos, y a la redefinición de la moral femenina basándola en el trabajo y dignificada por la educación y su participación en organismos públicos y en la regencia de colegios muestra este proceso de cambio de las mujeres (Mannarelli 1999:361).

"...Es halagador para el patriotismo que la mujer ayacuchana se encuentra ya perfectamente capacitada para ejercer no solamente funciones meramente administrativas, públicas y del hogar, sino también para los elevados disquisiciones de las motivaciones e ideas que la convivencia social pone a diario en juego y es altamente satisfactorio para el Centro Cultural Ayacucho, el contar con distinguidas intelectuales ayacuchanas, número que no cabe duda irá aumentando... ${ }^{6}$

Según los intelectuales, las mujeres educadas en tanto madres, serían quienes configurarían las ideas y principios nacionales; los conductos a través de los cuales se entregarían excelentes ciudadanos a la patria. Quiere decir, más allá de la función ideal de la mujer, el acceso a la educación les permitieran formar debidamente a los hijos dentro del hogar, asimismo contribuiría a la consolidación del futuro nacionalismo, mediante el acceso a la ciudadanía, la "nueva mujer" tenía que ser moderna. Entonces, la verdadera mujer es aquella que es dueña de sus acciones y jueza de su valor, se hace ella misma autora de su progreso, según la naturaleza que le ha sido dada.

Así quedó demostrado el surgimiento de un nuevo ideal de lo femenino y su papel social en el proceso de desarrollo de la región. Estos nuevos actores tuvieron como escenario de acción o tribuna al "Centro Cultural Ayacucho"; espacio que compartieron para sus debates y discusiones con otros literatos, periodistas y políticos más representativos de la región.

En consecuencia, la educación aparece en el imaginario de los intelectuales automáticamente como un instrumento que va a transformar la realidad social de las mujeres, al mismo tiempo como mecanismo que le permite su independencia del varón; ideales que pregonan los intento de modernización impuesta desde el estado; cuyos efectos se dejan sentir enormemente en la mentalidad de la elite regional.

En este sentido, las mujeres educadas actuaron como "adalides" de un nacionalismo universalizador que rompería definitivamente la barrera de la desigualdad contra el varón mediante la democratización de la alfabetización más allá de la esfera privilegiada, procurando de esta manera el surgimiento de un nuevo ideal de la mujer. En efecto, la educación se convierte en un elemento esencial y motor de cambio para alcanzar la igualdad entre los hombres y las mujeres. Como señala Foucault (1993:13) si el sexo está reprimido, es decir, destinado a la prohibición, a la inexistencia y al mutismo, el solo hecho de hablar de su represión, posee como un aire de transgresión deliberada. Quien usa ese lenguaje hasta cierto punto se coloca fuera del poder; hace tambalearse la ley; anticipa, aunque sea poco, la libertad futura."

6 Manuel E. Bustamante. Discurso pronunciado en conmemoración al aniversario del Centro Cultural de Ayacucho. En: Revista Huamanga, Núm. 49 y 50. Ayacucho, 1947. 
En sociedades profundamente fragmentadas como la huamanguina, donde las mujeres tenían asignados escenarios, espacios del hogar y la vida cotidiana donde debería obedecer y ser sumisa; el proceso de incursión femenina en la educación formal permitió la participación en la superación de las dicotomías que definían los roles en la sociedad. Es decir, la educación entendida como un proceso de socialización universal mediante el cual no solo se transmite conocimientos, sino que también valores, costumbres y formas de actuar con los que se pretende desarrollar el potencial de las mujeres, tanto personal como social sin discriminar a nadie por cuestiones físicas, sociales, intelectuales, siempre se ha utilizado como un medio de control de la sociedad.

De esta manera, las nuevas formas de relación entre los hombres y las mujeres, la participación y apropiación del espacio público por las mujeres y el proceso de constitución de la identidad femenina, a partir de su rol doméstico. Todos estos procesos situados en la problemática de la modernidad, en medio de una sociedad con rasgos patrimoniales en la cual la iglesia siguió conservando su poder. Observamos que la modernidad fue una experiencia compleja y contradictoria porque si bien erosionaba las jerarquías sociales, también creaba distinciones propias de la discriminación.

"... La educación tiene que cumplir urgentemente la nivelación social, corrigiendo las diferencias económicas, legados a las taras con que la historia forjo nuestra nacionalidad. Por tanto, es necesario solicitar la cooperación social sin distinción de sexos, edades, ni patrimonios hacia un movimiento de efectiva aculturación y de decidida regeneración. El problema del surgimiento nacional es pues, sobre todo un problema pedagógico...."7

Durante las primeras décadas del siglo XX los intelectuales huamanguinos estaban ávidos por capitalizar el espíritu liberal-positivista de la ciencia, la racionalidad, el progreso y la reformista. Era precisamente las posibilidades de regeneración social la que atraía a la vanguardia liberal y reformista a las versiones blandas de las doctrinas medioambientales. Donde la educación se muestra como mecanismo de progreso y de movilidad; si el temperamento psicológico de las mujeres era sobre todo producto del ambiente, entonces también podía ser positivamente moldeada por factores ambientales como la educación (Larson 2007.lbid).

Deesta manera, la falta de educación por el contrario generaba el abuso-la transgresión de las normas sociales. La educación se presenta como un medio de redención -que le permitió ser un nuevo sujeto social con capacidad de agencia, frente a aquella mujer degradada física y moralmente por los abusos cometidos por los varones.

En consecuencia, la aparición de nuevas circunstancias está modificando las diferencias entre hombres y mujeres y su papel social en el progreso de la región. El nuevo patrón hizo alusión a la capacidad intelectual de la mujer, promoviendo nuevas miradas acerca de la maternidad, el cuidado de los hijos y la constitución del hogar. A la vez les permite a las mujeres ser protagonistas de la renovación de los hombres y de la estructura de la sociedad, pues contribuye a su construcción comprometiéndose en la eliminación de la injusticia y trabajando por la paz.

7 Manuel E. Bustamante, En: Revista Huamanga, No. 49 y 50, Ayacucho, 1942. 
Con la difusión del pensamiento ilustrado esta concepción de la educación femenina empezó a cambiar y se promovió a crear conciencia sobre la necesidad de educar a las mujeres, promoviendo que ellas, a parte de las tareas manuales y la doctrina cristiana, recibieran una educación que las permitiera formar debidamente a los hijos dentro del hogar, aunque siempre manteniendo una prudente distancia del conocimiento.

"...Tengo la convicción de que en el progreso de la humanidad la mujer tiene un rol muy importante porque la innata bondad de su alma, la caridad cristiana y el altruismo que la animan, unidos a una sólida preparación, la capacitan para formar los espíritus de los hombres de mañana libres de los perjuicios que hoy la llevan a la lucha y a la destrucción..." 8

La mujer jugó un rol protagónico de gran trascendencia educadora y formadora en el seno familiar; es artesana laboriosa en la construcción del clima moral adecuado, convierte a la familia en escuela de la humanidad, de socialidad, donde se enseña y se realiza el cuidado y amor a los futuros ciudadanos de la región.

Esto expresa y simboliza que la educación fue pensada como elemento mediador que permita el acceso a la ciudadanía, patrones de vida familiar y la consolidación del futuro nacionalismo en un medio donde impera la marginación y discriminación hacia las mujeres. Como señala Alvizuri: “... en la comunidad, como en los diferentes pueblos de nuestro extremo departamento, de muchos años atrás funcionan numerosas escuelas y con el actual gobierno, el aumento del número de escuelas, ha seguido una progresión cada vez más creciente que halaga y estimula todo sentimiento genuinamente patriótico..."

Es en este tramo que las mujeres se convirtieron en partes esenciales del proyecto de modernización burguesa y se hizo evidente la necesidad de una adecuada preparación que los llevaría a cumplir su nuevo rol. Precisamente, se convirtieron en sujetos de programas educativos en función de los ciudadanos a los que debían formar dentro de la casa. Quiere decir que la ideología del nacionalismo empezó a producir esquemas educacionales para brindar a las masas femeninas "instrucción pública", "educación universal", o "pedagogía nacional".

La propuesta fue lanzada a inicios del siglo por la élite civilista que acababa de conquistar, tras varias décadas de esfuerzos frustrados o interrumpidos, el dominio del aparato del estado; tuvo, al lado una gran virtud: el diseño y la ejecución de un definido proyecto nacional: de aquel programa era la difusión de la instrucción la que fue pensada como la principal herramienta para conseguir la civilización del indígena y por ende su incorporación a la nación peruana. La escuela se constituía en el más eficaz medio de redención de la población aborigen, degradada física y moralmente por lo siglos del coloniaje (Contreras: 1996).

En consecuencia, recientemente estos mismos derechos fueron extendidos a las mujeres después de años de represión, prohibición y de adscripción a espacios específicos. Por esta razón, el discurso sobre la mujer en la prensa de este período revela el nuevo estereotipo de la mujer mestiza educada.

8 Revista Huamanga, Núm. 18. Ayacucho, 28 de febrero de 1939 
En el campo de la educación, diversos cambios en la sociedad regional han sentado las bases para la movilización y la mayor participación de las mujeres. El mayor acceso de la mujer a la educación formal y al mundo laboral la ha facilitado un mejor conocimiento de sus derechos y la incorporación a la experiencia de organización favoreciendo su participación social.

"...Con verdadera complacencia tenemos que comentar la actuación que tuvo lugar en el salón municipal el 30 de julio último, la que realzada con la asistencia de los elementos más destacados de nuestra sociedad tanto en el bello sexo como entre los caballeros..." (Editorialistas, año IV, Ayacucho 30 de septiembre de 1938).

De esta manera, los intelectuales representaron a las mujeres de la clase media huamanguina como aquellas que tuvieron acceso a una educación completa; es decir, representaron como "ya capacitadas" Es el sector social a la que algunos viajeros como Riva-Agüero (1995:129) representaba como la plebe mestiza ingeniosa y bien parecida, famosas en obras de platería y filigrana, en tejidos, etc. Mientras Rosa Escarcena representa como"cultas":

"Estas mestizas llegan a adquirir una instrucción más completa, pasan por la segunda enseñanza, llegan a ingresar muchas de ellas a la universidad y escuelas superiores".

Con el proyecto civilista el estado peruano planteó la incorporación de los sectores excluidos -como las mujeres para ello se dispusieron la gratuidad de la enseñanza primaria.

De esta manera, el cambio de siglo reveló un Perú que, según sus intelectuales más representativos, no se había consolidado ni política ni culturalmente como nación; por consiguiente había la necesidad de transitar hacia la modernidad que tanto deseaban.

Con la difusión del proyecto civilista, esta imagen y concepción de la educación femenina empezó a cambiar y se motivó a crear conciencia sobre la necesidad de educar a las mujeres, promoviendo que ellas, a parte de las tareas manuales y la doctrina cristiana, recibieran una educación que les permitiese formar debidamente a los hijos dentro del hogar, al mismo tiempo contribuya a la consolidación del futuro nacionalismo, mediante el acceso a la ciudadanía, la "nueva mujer" tenía que ser moderna.

El paradigma legitimar del discurso intelectual se sustentó en la concepción ideológica del nacionalismo; por ello, en el imaginario de los intelectuales la escasa concurrencia a las escuelas de parte de las mujeres se contraponía a los ideales del nacionalismo y a la modernización impuesta desde el estado, resultando verdaderos "escollos" de los modelos de vida familiar, de la enseñanza nacional, entorpeciendo de esta manera a nuestro futuro nacionalismo. Por ello, este ideal positivista debía ser entendida como un precepto general de carácter permanente cedido por elección pública en orden al bien común y que por esencia debía ser promulgada y obedecida.

9 Rosa Escarcena, en: Revista Huamanga, Núm.15. Año IV. Ayacucho, 30 de setiembre de 1938. 


\section{Conclusiones}

En el nuevo contexto histórico, los intelectuales huamanguinos terminaron elogiando a la emergencia del nuevo sujeto social, la mujer educada, ya que el proyecto de la élite era alcanzar una nación moderna, compuesta por ciudadanos portadores de derechos de libertad, igualdad y justicia.

A este grupo de mujeres podríamos denominar "vanguardistas", pues constituyeron un movimiento intelectual de avanzada para la época. Tuvieron como escenario de acción o tribuna al "Centro Cultural Ayacucho"; espacio que compartieron para sus debates y discusiones con periodistas y políticos más representativos de la región.

Finalmente, los efectos de las reformas hicieron posible el surgimiento de un nuevo ideal de la mujer huamanguina. El nuevo patrón hizo alusión a la capacidad intelectual de la mujer y su papel social en el progreso de la región y la consolidación de la nación. Bajo este nuevo paradigma, además se promovieron nuevas miradas acerca de la maternidad, el cuidado de los hijos y la constitución del hogar.

\section{BIBLIOGRAFÍA}

Bourdieu, P. (1998). La dominación masculina. Barcelona: Anagrama.

Caro, I. (2000). Política y cultura en Ayacucho (1918-1934): Entre la celebración del centenario de la batalla de Ayacucho y la formación del centro cultural Ayacucho. Ayacucho: UNSCH / Facultad de Ciencias Sociales.

Contreras, C. (1996). Maestros, mistis y campesinos en el Perú rural del siglo XX. Ediciones, documento de trabajo $N^{\circ} 80$. Lima: IEP.

Chatterjee, P. (2007). La nación en tiempo heterogéneo y otros estudios subalternos. Lima: IEP.

De La Riva-Agüero y Osma, J. (1995). Paisajes peruanos. Lima: PUCP.

Duby, G. (1992). Historia de las mujeres en occidente. Madrid: Taurus Minor.

Foucault, M. (1993). Historia de la sexualidad.1. La voluntad de saber. México: Siglo Veintiuno. Larson, B. (2007). Indios redimidos, cholos barbarizados: creando la modernidad neocolonial en la Bolivia liberal, 1900-1910. En: DE LOSADA, Aljovín y JACOBSEN, Nils (Editores): Cultura política en los andes (1750-1950). Lima: Fondo editorial UNMSM / IFEA.

Mannarelli, E. (1996). Las mujeres y sus vidas. En: Ideele, (84). Instituto de Defensa Legal.

Oliart, P. (1995). "Poniendo a cada quien en su lugar: estereotipos raciales y sexuales en la Lima del siglo XIX". En: Aldo Panfichi y Felipe Portocarrero (Eds). Mundos interiores: Lima 1850-1950. Lima: centro de investigaciones de la Universidad del Pacífico.

Urrutia, J. (2014). Aquí nada ha pasado: Huamanga siglos XVI-XX. Lima: IEP.

Valladares, O. (2012). "La incursión de las mujeres a los estudios universitarios en el Perú: 1875-1908. Disponible en: https://erevistas.uc3m.es/index.php/CIAN/article/ download/1544/758 


\section{Fuente Hemerográfica}

- Revista el Granito, órgano de la Sociedad Mixta de Preceptores. Fundada en el año de 1911, número 12.

- Periódico "La Patria", número 2, año, 1, Ayacucho, 1922.

- Revista Huamanga, órgano del Centro Cultural de Ayacucho. Fundada en el año de 1934. Números: 15, 16, 17,18, 49-50,52-53. 